\title{
A “Chacina do Pan" e a produção de vidas descartáveis ${ }^{\star}$
}

\author{
José Rodrigues Alvarenga Filho ${ }^{\star \star}$ \\ Centro Universitário Celso Lisboa, Rio de Janeiro, RJ, Brasil
}

\begin{abstract}
Resumo
Nosso artigo tem por alvo colocar em análise a tríade: segurança pública-mídia-produção de subjetividades na cidade do Rio de Janeiro no primeiro semestre do ano de 2007. Para tanto, tomamos como analisador a "Chacina do Pan" ocorrida no Complexo do Alemão para discutirmos: a) a produção de vidas descartáveis b) a cobertura da midiática; c) a produção de subjetividades amedrontadas. Utilizamos como ferramenta a obra de autores como Foucault, Agamben e Bauman. No momento em que o Rio de Janeiro receberá eventos como a Copa do Mundo de Futebol (2014) e as Olimpíadas (2016), torna-se imprescindivel a análise do atual contexto carioca. Concluímos que a "Chacina do Pan" foi o efeito de uma conjugação de forças que, aproveitando-se da realização do megaevento esportivo na cidade, intensificou os processos repressivos e exterminadores sobre os segmentos mais pobres da população. Extermínio para garantir a "paz" e a segurança da cidade.
\end{abstract}

Palavras-chaves: megaeventos esportivos; Rio de Janeiro; vidas descartáveis; produção de subjetividades.

\section{"Slaughter Pan" and production of disposable lives}

\begin{abstract}
Our article is targeted as an analysis of drug safety public - media - production of subjectivities in the city of Rio de Janeiro in the first half of 2007. Therefore, we take as the analyzer "Slaughter Pan" took place in the Complexo do Alemão to discuss: a) the production of disposable lives b) the coverage of the media, c) the production of subjectivities frightened. Used as a tool to work of authors such as Foucault, Agamben and Bauman. The moment that Rio de Janeiro will receive events such as the FIFA World Cup (2014) and the Olympics (2016), it is essential to analyze the current context of Rio. We conclude that the "Slaughter Pan" was the effect of a combination of forces, taking advantage of the completion of mega sports events in the city, intensified repressive processes and exterminators on the poorest segments of the population. Extermination to ensure "peace" and security of the city.
\end{abstract}

Keywords: sport mega events; Rio de Janeiro; disposable lives; production subjectivities.

\section{Introdução}

Dará um pouco mais de trabalho porque precisaremos de mais homens, mas isto não vai impedir a retomada dessas comunidades. Este será um ano marcado por três pés: Pan, PAC e pau.

(Marcus Jardim, em 2007, comandante do $16^{\mathrm{a}}$ BPM, Olaria, Rio de Janeiro)

19 vagabundos mortos? Essa foi a melhor noticia que eu li desde a faxina do Carandiru. Vamos continuar torcendo pra esse número subir amanhã pra 50, depois de amanhã pra 100 e assim por diante, até exterminar todos esses desgraçados. Parabéns a todos os envolvidos na operação. Merecem promoção imediata, com aumento de salários.

(Comentário de um leitor sobre a matéria do Globo Online [COSTA, A. C. et al., 2007, online] ${ }^{1}$

Nosso artigo nasce a partir do texto escrito em nossa dissertação de mestrado em Psicologia e, sobretudo, pela necessidade de contarmos às histórias que estamos dispostos a esquecer. As histórias sobre nossos medos e a maneira como estes nos aprisionam; as histórias sobre nossas misérias e a maneira pela qual estas nos desumanizam; as histórias sobre nossos silêncios, nossas apatias e desesperanças.

\footnotetext{
^ Fonte de financiamento: Coordenação de Aperfeiçoamento de Pessoal de Nível Superior (CAPES)

$\star \star$ Endereço para correspondência: Centro Universitário Celso Lisboa. Rua 24 de Maio, 797 - Engenho Novo. CEP: 20950092 - Rio de Janeiro, RJ - Brasil. E-mail:jraf.85@gmail.com

"Mega operação no Alemão deixa 19 mortos".
}

Contudo, não colocamos em análise a "Chacina do Pan" apenas para produzir mais um texto acadêmico. Escrevemos, sobretudo, por acreditarmos na potência do pensamento crítico e no uso das pesquisas enquanto ferramentas (DELEUZE; FOUCAULT, 2006) para questionar e potencializar a invenção de outras realidades. Escrevemos porque nutrimos esperança, não porque a perdemos. Ademais, escrever é um trabalho ético, pois “escrever é lutar, resistir [...] É uma tarefa política, portanto" (BARROS, 2009, p.28).

Por outro lado, é preciso deixar claro de onde falamos, bem como, afirmar que se escrevemos no plural é porque acreditamos que no coletivo nos fortalecemos e nos encontramos. Não fazemos coro com aqueles que se escondem atrás do "discursinho de ciência asséptica" (FLAUZINA, 2008), supostamente neutros e "desimplicados". Como escreve Paulo Freire (1996, p. 101), "minha voz tem outra semântica, outra música".

Nossa pesquisa é datada e localmente situada. O cenário do qual partiu nosso trabalho refere-se ao primeiro semestre do ano de 2007 e tem a cidade do Rio de Janeiro, especificamente o Conjunto de Favelas do Complexo do Alemão, zona norte, como palco.

\section{A megaoperação policial}

Em 2 de Maio de 2007, deu-se início o cerco da polícia em torno do Complexo do Alemão. A operação supostamente começou como uma resposta da polícia à morte de dois policiais do $9^{\mathrm{a}}$ Batalhão da Polícia Militar em Oswaldo Cruz, Zona Norte do Rio de Janeiro. No mesmo local onde os policiais foram mortos, o menino 
João Hélio Fernandes, em fevereiro de 2007, foi morto depois de ser arrastado preso ao cinto de segurança do carro roubado de sua mãe poucos meses antes.

O cerco da polícia as favelas do Complexo do Alemão se estendeu de maio até meados de julho de 2007. O ápice da ação policial foi no dia 27 de junho de 2007 quando uma "megaoperação policial", realizada em parceria entre os governos estadual e federal, envolveu mais de mil e trezentos policias, entre militares, civis e soldados da Força Nacional de Segurança Pública. Tal operação ainda contou com três carros blindados ("caveirões"), um helicóptero e uma dezena de viaturas.

O saldo total do cerco ao Complexo do Alemão, segundo Salles (2007), foi, a saber: 44 mortos e 78 feridos. Em um único dia, 27 de junho, foram mortas 19 pessoas que, de acordo com a Secretaria de Segurança Pública do Estado, eram suspeitos de participar do crime organizado no Complexo do Alemão. Usamos "chacina do Pan" para nos referirmos à morte destas 19 pessoas no dia 27 de junho de 2007.

No dia seguinte à megaoperação, a Comissão de Direitos Humanos da Ordem dos Advogados do Brasil (OAB) visitou o Complexo do Alemão, entrevistou moradores e colheu informações sobre o ocorrido. O então presidente da comissão, João Tancredo, apresentou denúncias à imprensa e ao Ministério Público sobre evidências que apontavam para mortes sem confronto, isto é, execuções.

Em outubro de 2007, relatório feito por peritos forenses designados pela Secretaria Especial de Direitos Humanos da Presidência da República, comprovou que houve execuções sumárias e arbitrárias no Complexo do Alemão. De acordo com o documento, a polícia gastou 70 balas para matar 19 pessoas, sendo que, pelo menos em dois casos, ${ }^{2}$ os laudos comprovam que houve execução.

Em nosso trabalho, focamos as análises em alguns pontos. Utilizando a "Chacina do Pan" como analisador, investigar: a) como se dá, hoje, na cidade do Rio de Janeiro, a produção de vidas descartáveis, isto é, vidas sem valor; b) como a cobertura de alguns veículos de comunicação de grandes corporações midiáticas cobriram e apoiaram a Chacina no Complexo do Alemão; c) que processos de subjetivação são estes que vem sendo produzidos e que corroboram na produção do medo e da insegurança e, também, em aplausos e apoio a políticas de extermínios das populações pobres cariocas.

\section{Racismo, refugo humano e vida nua.}

Mata mesmo [...] mata pelas costas, pela frente, com tiro na cara. Mata todo mundo, antes, durante e depois do Pan, da Copa do mundo, Olimpíadas de qlq (qualquer) merda, tem é (que) matar bandido pra ver se eles respeitam algo. Vcs (vocês) são engraçados... bandido não vê onde atira, em quem atira. Quero ver qdo (quando) for com vcs (vocês) ou com a familia de vcs (vocês)!! Matem todos!! Todos!!

(Comentário feito no vídeo Pan Americano 2007 e o

${ }^{2}$ Referimo-nos as mortes de José da Silva Farias Júnior (18 anos) e Emerson Goulart (26 anos).

\section{extermínio nas favelas $)^{3}$}

Segundo Foucault $(2003,2005)$, vivemos na era do biopoder. Trata-se do poder que toma como alvo de seu exercício a vida através, principalmente, das disciplinas dos corpos e a biopolítica das populações. Contudo, ao olharmos para história de nosso passado recente e, também, de nosso presente perceberemos que, inúmeras vezes, o biopoder parece fazer uso do antigo poder soberano de produzir a morte. Este, tinha o seu ápice no suplício dos corpos dos condenados.

De acordo Foucault (2005), o que torna possível esse aparente paradoxo - produzir a morte ao invés da vida - do biopoder é a utilização do racismo. Para o autor, o racismo tem duas funções principais: a primeira caracteriza-se por uma negatividade: operar um corte entre aqueles que devem viver e os que devem morrer. "Essa é a primeira função do racismo: fragmentar, fazer cesuras no interior desse contínuo biológico a que se dirige o biopoder" (FOUCAULT, 2005, p. 305).

Sua segunda função, pelo contrário, é "positiva": consiste em afirmar que para uma raça sobreviver é necessário que outras sejam eliminadas. Ou seja, o racismo vai estabelecer entre a vida dos membros de uma raça e outra, não uma relação do tipo de guerra, mas sim biológica. Neste sentido, o racismo se refere a uma desqualificação de uma raça em benefício de outra: para que uma determinada raça sobreviva é necessário que outra seja exterminada.

Assim sendo, o racismo é o dispositivo que permite que os Estados modernos, em plena era do biopoder, façam uso do poder soberano de produzir morte. A morte de um grupo, ou de uma pessoa, é justificada na medida em que seu extermínio é colocado como condição para sobrevivência dos demais. Na sociedade (feudal/monárquica) marcada pelo poder de soberania, matar era sinônimo deste tipo de exercício de poder. Contudo, na sociedade do biopoder, este não pode matar impunemente, pois a vida é o seu bem mais elevado.

A partir desta perspectiva, podemos pensar que a morte das 19 pessoas em 27 de junho no Complexo do Alemão se justifica, pois elas representavam uma suposta ameaça a toda sociedade. Desse modo, seu extermínio torna-se condição para a suposta sobrevivência dos demais. Suas vidas são indignas de serem vividas, pois sua sobrevivência pode representar um empecilho a saúde da sociedade. Daí, em parte, a "Chacina do Pan" ser aplaudida por centenas de pessoas no Rio de Janeiro. Afinal, mataram 19 supostos criminosos para que milhares pudessem viver em paz. Trata-se, evidentemente, de uma lógica fascista! Lógica esta presente diariamente em nosso cotidiano.

As estratégias racistas se camuflaram muito bem atrás de discursos ditos científicos e mitos como o da "democracia racial" (FLAUZINA, 2008). Um exemplo é o estadunidense Charles Murray que, durante o período do governo Reagan, escreveu um livro que "serviu como bíblia para a cruzada contra o Estado- providência"

${ }^{3}$ Endereço do vídeo no site Youtube: <http://www.youtube.com/watch?v=N3 5TyJ1Q4w>.

Fractal, Rev. Psicol., v. 28 - n. 1, p. 111-117, 2016 
(WACQUANT, 2001, p. 24). O cientista defendia que a ajuda aos pobres era a razão da crescente pobreza nos Estados Unidos. Em outra oportunidade, Murray, em parceria com o psicólogo de Harvard Richard Herrnstein, escreveu um livro que é "um autentico tratado de racismo erudito" (WACQUANT, 2001, p. 24): "sustenta que as desigualdades raciais e de classe na América refletem as diferenças individuais de "capacidade cognitiva". (WACQUANT, 2OO1, p. 24-25). Em artigo publicado na Inglaterra, Murray escreveu: "os homens negros são essencialmente bárbaros, para quem o casamento é uma força civilizadora"; "mulheres negras se deixam engravidar, porque sexo é bom e os bebês são uma gracinha" (WACQUANT, 2008, p. 48).

O que é preciso se explicitar é que a ideia de "raça" muito mais do que se referir a uma suposta natureza na qual se dividem os seres humanos, diz respeito a uma construção histórica, produzida a partir de determinadas relações de poder e que produz efeitos sobre a sociedade. Como escreve o historiador Joel Rufino dos Santos (2009, p. 172), "não há raça, mas racismo".

Por outro lado, os conceitos de "refugo humano" (BAUMAN, 2005) e o de "vida nua" (AGAMBEN, 2007) podem nos servir como ferramentas para pensar, a partir do analisador "Chacina do Pan", como as populações pobres da cidade do Rio de Janeiro são cotidiana e historicamente transformadas em lixo e como suas vidas se tornam, assim, descartáveis.

Para Bauman (2001, 2007), vivemos hoje, numa modernidade líquida, marcada pela fluidez e efemeridade dos relacionamentos e pela vida vivida em condições de precariedade e incertezas constantes. O autor (BAUMAN, 2005) sustenta que a produção de vidas humanas refugadas é um dos efeitos imediatos ao processo de modernização que caracteriza as sociedades. Ou seja, a modernidade caracteriza-se duplamente, por um lado, pela produção do novo, da novidade e, por outro, pela fabricação em massa de lixo humano, daquelas vidas que se tornaram inúteis ao funcionamento da máquina de produção capitalista e, por isso, são descartáveis.

Neste contexto em que seres humanos são transformados em dejetos, um dos maiores problemas políticos enfrentados pelos Estados na atualidade é, sobretudo, o que fazer com a massa crescente de lixo humano descartável. Trata-se, como escreve Bauman (2005, p. 13), de uma "crise na indústria de remoção de refugo humano".

A produção de refugo humano é "um efeito colateral da construção da ordem" (BAUMAN, 2005, p. 12), pois cada ordem circunscreve parte da população enquanto "inaptas" ou "indesejáveis". Da mesma maneira, a fabricação de lixo humano é majorada pelo "progresso econômico" que, ao desvalorizar modos anteriores de trabalho, priva parte da população de seus meios de subsistência. Como escreve Chauí (2006, p. 39), "a sociedade pós-industrial é a 'sociedade do descarte"".

Fractal, Rev. Psicol., v. 28 - n. 1, p. 111-117 2016
Para Bauman (2005, p. 14), um dos mais novos e promissores ramos de produção de pessoas refugadas é a "indústria da segurança". Ao mesmo tempo, esta, torna-se, também, "fator fundamental" no problema da remoção do lixo humano.

Vidas refugadas, pessoas descartáveis, seres humanos redundantes num mundo de incertezas e artificialidades. Relacionamentos efêmeros, nascidos sobre a luz do "descarte iminente". O cenário da "modernidade líquida" é pintado com cores tristes e sombrias. Ainda de acordo com Bauman (2005, p. 44), o "modelo ideal da pessoa excluída é o homo sacer". Este, "é a principal categoria de refugo humano estabelecida no curso da moderna produção de domínios soberanos ordeiros (obedientes à lei e por ela governados)" (BAUMAN, 2005, p. 45)

Para Agamben, vivemos hoje num momento em que o Estado de exceção se torna regra e a biopolítica se transforma, perigosamente, em "tanatopolítica". Segundo o autor (AGAMBEN, 2007), as raízes da biopolítica moderna já estavam fincadas no período da Grécia Antiga e expostas na distinção entre bios e zoé. Principalmente, pelo fato da zoé ser incluída na polis através de sua exclusão.

Os gregos não possuíam um único termo para se referirem aquilo que chamamos de vida. Para os mesmos, a ideia de vida era dupla e, por isso, usavam "dois termos, semântica e morfologicamente distintos, ainda que reportáveis a um étimo comum" (AGAMBEN 2 2007, p. 9): zoé representava a vida natural de todos os seres vivos, isto é, o simples fato de viver. Este termo podia ser usado para se referir a vida comum tanto de homens e animais, como de Deuses.

Por outro lado, o termo bios"era usado para se referir à vida entendida enquanto forma ou maneira de viver de um indivíduo ou de um determinado grupo. Diferentemente da zoé, que representava o simples fato de viver, a bios implica numa vida que possui relevância política; numa vida marcada pela linguagem, pela racionalização.

Agamben usará do obscuro conceito de homo sacer, retirado do antigo direito criminal romano, para pensar na inscrição da vida nua (termo retirado da obra de Walter Benjamin) nas relações de poder dos Estados modernos Ocidentais. O conceito de homo sacer traz um paradoxo: é uma vida insacrificável e, ao mesmo tempo, matável.

Assim sendo, o homo sacer representa, duplamente, uma vida que não pode ser levada a morte dentro dos meios sancionados pelo rito, mas que, contraditoriamente, sendo impunemente exterminada por qualquer um sua morte não representa um crime, muito menos um sacrilégio.

A vida nua é a vida alienada de qualquer direito e, por isso, matável. Empurrada para fora dos limites das regras sociais (das normas do direito, bem como, da sacralidade) e da humanidade, torna-se uma vida descartável. Sua inclusão na ordem jurídica se dá por sua exclusão da mesma. Uma vida impotente, castrada, despotencialiazada.

Agamben usa da figura do homo sacer para colocar em análise a própria política ocidental moderna e a maneira pela qual esta inclui a vida nua em seus cálculos 
e institui o Estado de exceção enquanto regra. De uma maneira ou de outra, em nossa contemporaneidade, todos nós nos tornamos vidas nuas, ou, "sobreviventes".

A partir da leitura de Agamben, podemos perceber que, em nosso presente, há uma conjunção de forças nas quais o poder sobre a vida e o poder que aniquila a vida se tornam paradoxalmente um único e mesmo poder. Neste contexto, a biopolítica descrita por Foucault (2003, 2005), transforma-se em "tanatopolítica" (AGAMBEN, 2007). Assim sendo, o homo sacer, longe de ser uma figura obscura e distante do direito criminal romano, se torna fatidicamente atual e presente nos cálculos da biopolítica contemporânea.

No mundo contemporâneo, desse modo, produzse em larga escala vidas refugadas. No Rio de Janeiro, cenário que tomamos como pano de fundo de nossa investigação, as forças que se conjugam na produção e extermínio das pessoas tidas como refugadas/redundantes são muitas. Dentre elas, podemos destacar, os discursos de determinados veículos de comunicação como atores sinistros da fabricação de vidas humanas refugadas. Como canta Chico Buarque, "mas o que eu quero lhe dizer é que a coisa aqui tá preta". ${ }^{4}$

\section{Mídia e produção de subjetividades}

No contexto de nosso trabalho interessou-nos, sobretudo, colocar em análise os discursos da mídia como potentes produtores de subjetividades. Para tanto, fazemos uso do conceito de processos de subjetivação tal como problematizado por Félix Guattari em sua obra. Assim, falaremos, ainda que de maneira breve, da articulação entre mídia e processos de subjetivação.

No que concerne às subjetividades, para Guattari (1992; GUATTARI; ROLNIK, 1996), as mesmas não são uma essência inerente ao ser humano, não se referindo a uma suposta natureza humana. Não são transcendentes, mas antes, imanentes, ou seja, processuais. Elas são produzidas "por instâncias individuais, coletivas e institucionais" (GUATTARI, 1992, p. 11)

As subjetividades referem-se aos diferentes modos de experimentação do mundo: a maneira como vemos, ouvimos, sentimos, nos relacionamos com os outros. Elas dizem respeito às maneiras como vivemos e experimentamos a vida. Como escreve Guattari (1992, p 11), "a subjetividade, de fato, é plural, polifônica".

A partir deste ponto de vista, as subjetividades são pensadas, então, como uma produção histórica que se dá a partir de inúmeros agenciamentos/atravessamentos sociais e, por isso, elas não são aquilo que está dado a priori. Elas são os efeitos de múltiplas produções e, ao mesmo tempo, são produtoras também.

Guattari e Rolnik (1996) usam a expressão "capitalística" ao invés de capitalista, para designar um modo de subjetivação que se tornou hegemônico com a emergência do sistema de produção capitalista. Para os autores, as forças capitalísticas não produzem apenas capitais, produzem subjetividades. A subjetividade, como diz o autor, é a matéria prima fundamental de toda e qualquer produção capitalística.

A mídia é um dos principais equipamentos sociais de produção de modos de subjetivação. Segundo Coimbra (2001, p. 29), a mídia produz "esquemas dominantes de significação e interpretação do mundo e que os meios de comunicação, "falam pelos e para os indivíduos".

No mercado globalizado das notícias, os discursos midiáticos produzem certos processos de subjetivação. No primeiro semestre de 2007, houve uma grande produção de discursos midiáticos que "falavam" para seus leitores do perigo da realização dos jogos Pan Americanos na cidade do Rio de Janeiro. Tais discursos cooperaram para a produção de um clima de medo e insegurança na cidade. Obviamente, existem outros fatores implicados na produção do medo e da insegurança.

Segundo Batista (2003), a difusão do medo do caos no Brasil possui um papel estratégico no controle e disciplinamento das massas. Neste contexto, o papel desempenhando pelos discursos midiáticos não é de coadjuvante. A mídia é protagonista de espetáculos nos quais são encenadas peças que a mesma ajudou a escrever.

A narrativa midiática oferece ao público uma versão da história, uma determinada interpretação dos fatos que, contudo, é vendida como se fosse a única verdade possível. É assim que diariamente os veículos de comunicação fabricam consensos sobre certas práticas, consolidam valores e criam heróis ou vilões no teatro do cotidiano. Como escreve Arbéx Júnior (2005, p. 103), "os fatos, transformados em notícia, são descritos como eventos autônomos, completos em si mesmos".

Por este viés, podemos dizer que a mídia é tão poderosa porque ela tem a capacidade de produzir, em grande escala, subjetividades submissas aos seus interesses, ou seja, aos interesses do capital globalizado. Como escreve Coimbra (2001, p. 29), a mídia "não nos indica somente o que pensar, o que sentir, como agir, mas principalmente nos orienta sobre o que pensar, sobre o que sentir".

Para o desenvolvimento de nosso trabalho, utilizamos os discursos de diferentes meios de comunicação publicados, principalmente, no primeiro semestre de 2007. Selecionamos, neste artigo, dois veículos de comunicação para colocarmos em análise como os mesmos cobriram a megaoperação no Complexo do Alemão em 27 de junho de 2007. Escolhemos as publicações das duas maiores revistas semanais de circulação no país: Revista Época (Editora Globo) e a Revista Veja (Editora Abril). Ambas atingem um grande público classe média.

A invasão do dia 27 de junho no Complexo do Alemão virou matéria de capa de jornais, revistas e ganhou muito destaque em programas da TV - alguns chegaram a transmitir trechos da operação policial ao vivo em suas emissoras. No entanto, podemos concluir que uma das principais ideias sustentadas pela cobertura de diferentes veículos de comunicação da grande mídia 
sobre a invasão do dia 27 de junho foi: a operação foi um grande sucesso e, tornou-se assim, um marco no Brasil no que tange ao combate a criminalidade.

Contudo, como pode uma operação que envolve mais de 1000 policiais, que não prende nenhum suspeito, que gasta 70 balas para matar 19 pessoas, que apreende um número insignificante de armas e drogas ter sido um sucesso? Ser prova de "inteligência, planejamento e determinação"? (MASSON; AZEVEDO; FERNANDES, 2007). A Revista Época, por exemplo, classificou a operação como "um ataque inovador". Historicamente, matar pobres em nome da segurança da sociedade não é algo novo.

Neste sentido, o discurso da revista tratou a operação policial no Alemão não como mais uma intervenção da polícia numa favela carioca, mas, antes, como a tentativa de afirmação do Estado contra o caos, a desordem ou, usando o vocabulário da Época, contra a "barbárie". A sorte da população do Rio, bem como, o destino da cidade estava sendo traçado a ferro e fogo nas ruas esburacadas, nas vielas estreitas, nas casas de tijolos vermelhos do Complexo do Alemão.

Por outro lado, a Revista Veja (SOARES, 2007) classificou a invasão ao Alemão de "uma guerra sem precedentes". A Revista não fez cobertura muito diferente de sua concorrente Época, e ajudou a produzir um consenso de que: a) o Complexo do Alemão é a fonte de grande parte dos problemas de segurança pública no Rio; b) a operação policial - que deu se a partir de maio de 2007 e durou até meados de julho do mesmo ano no conjunto de favelas deveria ser enérgica para que o Estado vencesse o tráfico e pudesse, assim, recuperar toda aquela região; c) a megaoperação policial de 27 de junho foi um marco no combate a "criminalidade", ou seja, um verdadeiro e aplaudido sucesso.

Contudo, as duas revistas não se preocuparam em investigar se as inúmeras denúncias de violações aos direitos humanos, tortura e violência policial contra a população do Alemão tinham fundamento. Timidamente, as mesmas noticiaram que houve denúncias, mas, ao mesmo tempo, não se deram ao trabalho de fazer qualquer investigação. Ou, se fizeram investigação não a publicaram, posteriormente.

A Revista Veja chegou a afirmar que "quase todos os feridos, aliás, são moradores atingidos pelos próprios traficantes, que pretendiam jogar a opinião pública contra a polícia" (SOARES, 2007). Em nossa pesquisa, não encontramos nenhum relato, seja da polícia, de jornalistas ou de moradores do Complexo do Alemão, que corroborem a afirmação acima.

Ao tomarmos como analisador os discursos das Revistas Veja e Época, percebemos que a política de verdade adotada por ambas são muito próximas. As duas cooperaram de maneira sinistra para que a operação policial no Conjunto de Favelas do Complexo Alemão em 2007 fosse vista, pelo grande público classe média leitor de suas revistas, como um acontecimento inovador que demonstrava como o "combate a criminalidade" deveria ser tratado no Rio de Janeiro e no Brasil. Contudo, nos perguntamos: o que há de inovador na prática policial de invasão de comunidades e mortes de moradores?

Os dados estatísticos que poderiam demonstrar que a megaoperação policial no Complexo do Alemão no dia 27 de junho representou um verdadeiro fracasso são usados pelas revistas Veja e Época como se representasse uma das provas do sucesso da invasão policial. Por exemplo, ao invés de dizerem que a polícia prendeu apenas 14 armas, as revistas enfatizam que dentre estas havia uma perigosa metralhadora anti-aérea.

Ao se posicionarem ao lado do governo fluminense e de sua política de segurança pública transformada em política pública de extermínio dos pobres, ambas as revistas - Veja e Época - se tornaram, no nosso entender, apêndices da máquina mortífera montada pelo Estado para aniquilar aqueles que se tornam, diariamente, seres humanos refugados ou descartáveis.

Neste sentido, que os discursos da grande mídia serviram como apêndice da "máquina mortífera" (BAUMAN, 1998) montada pelo Estado para reprimir e exterminar as classes pobres marginalizadas. Aliás, não é de hoje que o Estado brasileiro e as grandes corporações de mídia fazem parte de algum pacto sinistro. A mídia usou de sua capacidade de produzir verdades e consensos através da produção discursiva para nos fazer crer na iminente ameaça da criminalidade contra os jogos Pan Americanos. Para tanto, a estratégia utilizada foi a da exposição diária e sensacionalista de atos de criminalidade na cidade do Rio.

Por outro lado, quando, enfim, estava intensificado um clima de medo e insegurança no Rio as vésperas do Pan, o Complexo do Alemão foi invadido a luz do dia e sob os holofotes da mídia. O ineditismo desta invasão ao Alemão está, por um lado, na grande quantidade de homens envolvidos na operação - mais de 1.000 -, bem como, no modo pelo qual a mídia fez a cobertura sensacionalista da invasão estando lado a lado com os policiais subindo os morros do Alemão. Percebemos, aqui, um paralelo com a nova modalidade de cobertura jornalística forjada na recente Guerra do Iraque.

A história oficial, aquela que ganhou a capa das revistas, foi a de que a "Chacina do Pan" nunca aconteceu. $\mathrm{O}$ que ocorreu foi a matança executada pelas forças do Estado - que detém o monopólio da violência - , apoiada pelos grandes grupos de mídia - mas não apenas por estes - e aplaudido por grande parte da população carioca. Tudo em nome da segurança, dos jogos Pan e da paz da cidade. Curiosamente, quando estivemos no Complexo do Alemão pouco tempo depois da "Chacina do Pan" encontramos, sem muita dificuldade, adolescentes carregando fuzis e pistolas e drogas sendo vendidas à luz do dia a poucos metros de onde ficavam os soldados da Força Nacional de Segurança. Depois da megaoperação tudo voltou a ser como era enquanto o Estado e a mídia falavam em paz. Estranha paz. 


\section{Conclusão}

A questão que levantamos não é a de apontar possíveis culpados ou inocentes, mas de colocarmos em análise o contexto no qual tornar-se possível - e, infelizmente, até "natural" - que a realização de megaeventos esportivos sirvam como desculpa para intensificação e criação de políticas públicas de repressão e extermínio dos pobres. Do mesmo modo que o Estado do Rio de Janeiro possui hoje, vide Copa de 2014 e Olimpíadas de 2016, um agenda esportiva, há, também, uma agenda de criminalização da pobreza e dos movimentos sociais.

Apesar da produção constante do silenciamento, do medo, da insegurança, vozes dissonantes soam rebeldes pelos cantos da cidade. Como afirmou Foucault certa vez, sociedade disciplinar não significa "sociedade disciplinada". As relações de poder que fabricam subjetividades capitalísticas podem, também, ser usadas para produzir processos de singularização.

Se há um modo de subjetivação dominante que implica em determinadas posturas/sentimentos/ pensamentos diante da sociedade, da vida, do consumo etc. há, também, modos de subjetivação que escapam das serializações das subjetividades capitalísticas. São subjetividades desobedientes, que driblam as fôrmas subjetivas dominantes e inventam outras maneiras de viver, de sorrir, de amar, de protestar etc. A este processo criativo Guattari (GUATTARI; ROLNIK, 1996) chamou de "processos de singularização".

A pesquisa realizada representa apenas um recorte dentre as inúmeras possibilidades de análise que podem ser feitas a partir do acontecimento "Chacina do Pan". Privilegiamos determinados autores e livros e deixamos de lado outros tantos, reconhecidamente importantes. Mas como em qualquer trabalho, é preciso se fazer seleções e cortes de material. Esperamos que o material que reunimos e produzimos torne-se útil para outras pesquisas e questionamentos. Enfim, para novas lutas.

Concluímos que a "Chacina do Pan" foi o efeito de uma conjugação de forças que fez uso da realização do megaevento esportivo Jogos Pan Americanos para intensificar a agenda repressiva e exterminadora do Estado contra as classes pobres marginalizadas. Por este viés, os veículos de comunicação das grandes corporações midiáticas não apenas aplaudiram a Chacina, como ajudaram a produzir um clima de medo e insegurança tornando a megaoperação policial um acontecimento possível e, sobretudo, aclamado.

Por outro lado, hoje o Rio de Janeiro se tornou sede de dois grandes megaeventos esportivos, entre outros: a Copa do Mundo de Futebol (ocorrido em 2014) e as Olimpíadas (2016). A cidade está sendo preparada para a realização dos mesmos. O desafio que enfrentamos agora é lutar para não permitir que novas chacinas e violências aconteçam em nome da realização de tais eventos. Práticas de violência em nome da paz. E como é tão estranha a paz quando é feita de guerra; quando produz corpos dóceis, subjetividades submissas e vidas descartáveis.

\section{Referências}

AGAMBEN, G. Estado de exceção. São Paulo: Boitempo, 2007.

ARBÉX JÚNIOR, J. Showrnalismo: a notícia como espetáculo. São Paulo: Casa Amarela, 2005.

BARROS, R. B. Grupo: a afirmação do simulacro. Porto Alegre: Sulinas/UFRGS, 2009.

BATISTA, V. O medo na cidade do Rio de Janeiro. Rio de Janeiro: Revan, 2003.

BAUMAN, Z. Modernidade e holocausto. Rio de Janeiro: J. Zahar, 1998.

BAUMAN, Z. Modernidade líquida. Rio de Janeiro: J. Zahar, 2001.

BAUMAN, Z. Vidas desperdiçadas. Rio de Janeiro: J. Zahar, 2005.

BAUMAN, Z. Vida líquida. Rio de Janeiro: J. Zahar, 2007.

CHAUÍ, M. Simulacro e poder: uma análise da mídia. São Paulo: Fundação Perseu Abramo, 2006.

COIMBRA, C. Operação Rio: o mito das classes perigosas. Rio de Janeiro: Oficina do Autor, 2001.

COSTA, A. C. et al. Megaoperação no Alemão deixa 19 mortos. Extra, Globonews, CBN, Reuters e O Globo Online. 27 jun. 2007. Disponível em: <http://extra.globo.com/noticias/rio/ megaoperacao-no-alemao-deixa-19-mortos-681274.html>. Acesso em: 12 jul. 2007.

DELEUZE, G.; FOUCAULT, M. Os intelectuais e o poder. In: MOTTA, M. B. (Org.). Estratégia, Poder-Saber. Rio de Janeiro: Forense Universitária, 2006. Coleção Ditos \& Escritos, v. 4 , p. $37-47$.

FLAUZINA, A. L. Corpo negro caído no chão: o sistema penal e projeto genocida do Estado brasileiro. Rio de Janeiro: Contraponto, 2008.

FOUCAULT, M. História da sexualidade: a vontade de saber. São Paulo: Graal, 2003. v. 1.

FOUCAULT, M. Em defesa da sociedade. São Paulo: Martins Fontes, 2005.

FREIRE, P. Pedagogia da autonomia. São Paulo: Paz e Terra, 1996.

GUATTARI, F. Caosmose: um novo paradigma estético. Rio de Janeiro: 34, 1992.

GUATTARI, F.; ROLNIK, S. Micropolitica: cartografias do desejo. Petrópolis: Vozes, 1996.

MASSON, C.; AZEVEDO, S.; FERNANDES, N. Os novos rumos da guerra contra o crime. Revista Época, Rio de Janeiro, n. 467 , p. 62-66, jun. 2007.

PAN-AMERICANO 2007 e o extermínio nas favelas. Produção: Caô Produções. Video. Disponível em: <https:// youtu.be/N3_5TyJ1Q4w>. Acesso em: 18 jun. 2013.

SALLES, M. Complexo do Alemão: entre a perversidade da mídia e a perversidade da polícia. Revista Caros Amigos, São Paulo, ano XI, n. 125, p. 34-39, ago. 2007. 
SANTOS, J. R. Mídia e produções de subjetividade: questões do racismo. In: CONSELHO FEDERAL DE PSICOLOGIA. Mídia e psicologia: produção de subjetividade e coletividade. Brasília: CFP, 2009. p. 172-174.

SOARES, R. Ataque à cidadela do tráfico. Veja [online], n. 2009, maio de 2007. Disponível em: <http://veja.abril.com. br/acervodigital/home.aspx? edicao $=2009 \& p g=08>$. Acesso em: 21 ago. 2007.

WACQUANT, L. As prisões da miséria. Rio de Janeiro: J. Zahar, 2001.

WACQUANT, L. As duas faces do gueto. Rio de Janeiro: Boitempo, 2008.

Recebido em: 21 de julho de 2013 Aceito em: 25 de setembro de 2015 